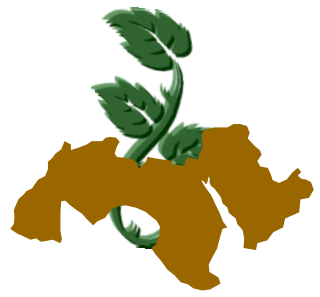

Arab Univ. J. Agric. Sci., Ain Shams Univ., Cairo, 15(2), 535-542, 2007

\title{
DEVELOPMENT AND REPRODUCTION OF THE TWO PREDATORY MITES EUSEIUS scutalis AND TYPHLODOROMIPS swirskii (ACARI: PHYTOSEIIDAE) AS AFFECTED BY LEAF TEXTURE OF STRAWBERRY PLANTS
}

\author{
Elsawi, Sawsan ${ }^{1}$, A. and Alazzazy, Mahmoud ${ }^{2}, \mathrm{M}$. \\ 1- Plant protection Department, National Research Centre, 12622 Dokki, Cairo, Egypt \\ 2- Department of Agricultural Zoology and Nematology, Faculty of Agriculture, Al-Azhar \\ University, Nasr city, Cairo, Egypt.
}

Keywords: Strawberries, Biological aspects, Phytoseiidae, Leaf texture

\begin{abstract}
The predatory phytoseiid mites Euseius scutalis (El-Badry) and Typhlodrompis swirskii (AthiasHenriot) successfully developed and reproduced on strawberry leaves, infested with mymphs of the two-spotted spider mite Tetramychus urticae kock as prey, of both Yaeel (smooth slight hairy) and Vantana (rough dense hairy) cultivars indicating a different effect of leaf surface on their behaviour at $27^{\circ} \mathrm{C}$ and $70 \% \mathrm{RH}$. Yaeel leaf was the most appropriate surface and Vantana ones was the least. Longevity was the greatest on Yaeel (31.92 and 28.48 days) and the shortest on Vantana (19.40 and 15.50 days) for each predator, respectively. The total number of eggs/ female was 39.00 and 41.34 on Yaeel and 21.02 and 19.68 on Vantana, respectively. Population of the two predators multiply 29.21 and 27.41 in a generation time of 15.78 and 13.93 days on Yaeel, whilst they were $(\mathrm{Ro}=14.77$ and 14.79$)$ and $(\mathrm{T}=14.26$ and 12.55 days)on Vantana, respectively. Life table parameters also indicated that the smooth Yaeel leaves are better host-plants for predators in terms $\mathrm{rm}$ and $\mathrm{e}^{\mathrm{rm}}$. Trichomes characteristics on midrib and blade of Yaeel and Vantana strawberry leaves were determined.
\end{abstract}

\section{INTRODUCTION}

Increasing the demand of fresh strawberry, Fragaria ananassa Deuchesne, particularly in foreign markets, encourages growers to expand strawberry cultivations in Egypt. Several high quality strawberry cultivars, as well, have been introduced and as a result, several pests and diseases have prevailed the fields. Some of them cause important economical damage, such as the two-spotted spider mite, Tetranychus urticae Kock. Now, it has been documented that the predatory phytoseiid mites could have acheived excellent control for phytophagous mites and several small insects (Graut and Richards, 1992; AbouAwad et al 2000 and 2005), although there are several factors limit the efficiency of these natural enemies. Among these factors, leaf trichomes and morphological structures. Trichomes of host-plant could cause instability, variable and season-related mortalities of the predator by entrapment on the host leaves.

On the other hand, strawberry leaves have a large number of stomata $\left(300-400 / \mathrm{mm}^{2}\right)$ compared to many other plants, consequently, the leaves lose large amounts of water through transportation (Maas, 1984). The glandular trichomes, as well adversely affect predators by direct contact or by exposure to their volatiles (Kennedy et al 1991; Sutterlin and van Lenteren, 1997). The difference in behaviour and efficiency of the predatory phytoseiid mites, however, may also be related to the leaf texture (Elsawi, 1980; Aly, 1994; Ibrahim, 1997; Abou-Elella, 1998; El-Banhawy et al 2000; Saber and Momen, 2000).

In this study, the effect of high density of strawberry trichomes and the other almost trichome-free on the development and reproduction of two predatory plytoseiid mites, common on strawberry cultivars, i.e. Euseius scutalis (El- 
Badry) and Typhlodrompis swirskii (AthiasHenriot) was investigated. Life table parameters were also determined.

\section{MATERIALS AND METHODS}

Adult females of the predatory phytoseiid mites E. scutalis and T. swirskii were obtained from mass cultures maintained on the two-spotted spider mite T.urticae in experimental glass house at the National Research Centre, Dokki.

To study the effect of leaf texture, either rough or smooth, on the predators biology, two different strawberry cultivars were selected. Vantana with high density of trichomes and Yaeel with almost trichome- free, respectively.

\section{1- Effect of strawberry leaf texure on oviposi- tion, longevity and life table parameters}

Predators were transferred to rearing substrates consisting of sweet potato leaves heavily infested with $T$. urticae. Fresh eggs ( 24 h old) were used for biological studies. Leaf discs of both strawberry cultivars, $1.5 \mathrm{~cm}$ in diameter, were used as rearing arenas in Petri dishes with the upper surfaces of the leaves placed downwards on water- saturated cotton. Newly hatched larvae (35 for every test) were confined, singly, in these arenas and supplied with T.urticae nymphs. Observations of the development were done twice a day, and reproduction and survival once a day. Every $4-5$ days, the predators were transferred to new strawberry arenas and the hatched larvae reared until maturity. After the last moulting, males were put with the females for mating, Males were then transferred to new arenas and individually of each predator reared until their death. The eggs of the predators were removed daily from the arenas. An abundance of fresh nymphs of T.urticae as prey was replenished daily. The effectiveness of E.suctalis and T.swirskii as predators were tested in the laboratory at $27 \pm 1^{\circ} \mathrm{C}$ and $70 \pm 5 \% \mathrm{RH}$, and $12 / 12 \mathrm{~h}$ light/dark periods.

Data abtained were statistically analyzed by $\mathrm{T}$ test and life table parameters were calculated according to Hulting et al (1990).

\section{2- Examination and photographing of straw- berry leaf texture}

To determine the smooth and roughness of each strawberry cultivar, samples $\left(4 \mathrm{~mm}^{2}\right)$ from leaf area were promoted and immediately fixed in glutaraldehyde $(2.5 \%)$ from $24 \mathrm{~h}$ period at $4^{\circ} \mathrm{C}$, then post-fixed in osmium tetraoxide $\left(1 \% \mathrm{O}_{5} \mathrm{O}_{4}\right)$ for one hour at room ambient temperature (Harley and Fergusen, 1990). Through ascending concentrations of acetone, samples were dehydrated and coated by gold sputtering. Examination and photographing were carried out by Teal Scanning Electron Microscope (T330A) in the Central Laboratory of Faculty of Agriculture, Ain-Shams University.

\section{RESULTS AND DISCUSSION}

\section{Characterizing the strawberry trichomes}

Trichomes density, thickness and length on leaf midrib and balde of Yaeel and Vantana strawberry cultivars demonstrated in Table (1) and Figs. (1-4). Trichome length and density were an average of $1371 \mathrm{um}$ and 41.93, respectively, on midrib Vantana cultivar, whilst they were 709.93 um and 19.13 in Yaeel showing significant differences. Density of trichomes on leaf blade was significantly higher in Vantana (10.3) compared with that of Yaeel cultivar (5.9). On the other hand, no significant detected in the length of blade trichomes for both strawberry cultivars. It is worth noting that thickness of midrib and blade trichomes were almost the same (Table 1). In general, midrib trichomes of Vantana cultivar were denser and have more sharply and pointed end than those of Yaeel strawberry plants.

Impact of strawberry leaf texture on development and fecundity of phytoseiid predators.

Results obtained on the duration of the different developmental stages and adult oviposition of E. scutalis and T.swirskii on both strawberry cultivars (Yaeel and Vantana) irrespective of smooth and roughness, respectively, are given in (Tables 2 \& 3). Results clearly indicated that the immature stages of the two predatory mites developed to the adult stage on smooth leaves in a comparatively shorter periods, averaged 6.83 and 6.35 days, than their counterparts on roughness ones as their developmental durations averaged 8.30 and 7.09 days for E. scutalis and T.swirskii, respectively. This difference was significant $(\mathrm{P}<0.01)$ in favour of Yaeel cultivar. Total longevity was greatest on smooth Yaeel leaves and shortest on roughness Vantana for the two predators, with the same trends observed in the adult of oviposition periods. 
Arab Univ. J. Agric. Sci., 15(2), 2007 
On smooth Yaeel leaves, females of E.scutalis and T. swirskü laid a greater number of eggs, averaged 39.00 and 41.34 eggs/ female during 28.08 and 27.52 days, with a daily rate of 1.39 an 1.52 eggs than those of reared on roughness Vantana which laid an average of 21.02 and 19.68 eggo/ female during 15.50 and 13.86 days, with a daily rate of 1.35 and 1.43 eggs, respectively. It is of interest to note that the life span of both predatory phytoseiid mites also showed a distinct difference linked to smooth Yaeel cultivar.

The effect of strawberry leaf texture on life table parameters is shown in Table (4). Population of the predacious mites E. scutalis and T. swirskii could multiply 29.21 and $27.41 \quad(\mathrm{Ro}=29.21$ and 27.41) in a generation time of 15.78 and 13.93 days $(T=15.78$ and 13.93) when predators reared on smooth yaeel leaves, while they were $(\mathrm{Ro}=$ 14.77 and 14.79) and $(T=14.26$ and 12.55) on roughness Vantana cultivar, respectively. Under given conditions, the intrinsic rate of increase (rm) were ( 0.213 and 0.237 individuals/female/day) on Yaeel and (0.188 and 0.191) on Vantana; while the finite rate of increase $\left(\mathrm{e}^{\mathrm{rm}}\right)$ were $(1.238$ and 1.268 female daughters/female/ day) and (1.207 and 1.239) on the two strawberry cultivars and predators, respectively. It was found, as well, that sex ratios for the two predators were the same. It is therefore concluded that smooth Yaeel leaves are a better host-plant for E. sculalis and T.swirskii in terms rm and $\mathrm{e}^{\mathrm{rm}}$.

\section{DISCUSSION}

The predatory phytoseiid mites, E.scutalis and T.swirskii successfully developed and reproduced on strawberry leaves of Yaeel (smooth dense hairy) and Vantana (rough dense hairy) indicating an effect of leaf surface on their behaviour. It was noted that the Yaeel leaves promoted a longer longevity, as well as, a longer oviposition period and consequently a marked higher number of eggs deposition; whereas, in contrast, Vantana leaves led to a shorter longevity and the predatory efficiency was extremely reduced. This means that some host plants favoured more suitable conditions for the development and biological activities of the phytoseiid predators. These findings are in accordance with those of several workers who reported that other predatory phytoseüd species showed different behaviour according to roughness of the plant surface. Generally, Phytoseius spp. are restricted to hairy plant leaves (Walter, 1992). Duso (1992) found that Amblyseius ober- rans (Oud.) and Typhlodromus pyri (Scheuten) developed and reproduced better on smooth or slightly hairy leaves. Aly (1994) indicated that Amblyseius swirskii Athias-Henriot developed and reproduced on various leaf surfaces, but grape frut (smooth leathery) was the best and guava (with coarse network of veins) was the worst. However, phytoseiid's preference for smooth surfaces, may be due to that the trichome density can hinder the searching of predator either by mechanically hindering the movement or through sticky exudates causing the mite to spend a large proportion of its time cleaning itself (Price et al 1980; Van Haren et al 1987).

Herein, it cuoud be concluded that both Yaeel and Vantana strawberry leaves are adequate medium for the development and reproduction of E.scutalis and T.swirskii, although comparatively smooth Yaeel cultivar proved to be the most appropriate surface of the two predators. On the other hand, the biology of the predators are adversely affected by rough dense hairy of Vantana leaves as a rearing substrate. Additional study is required to find relationships between trichome density and/ or trichome head size and the percentage of predator entrapped.

\section{REFERENCES}

Abou-Awad, B.A.; B.M. El-Sawaf; A.S. Reda and A.A. Abdel-Khalek (2000). Environmental management and biological aspects of two eriophyoid fig mites in Egypt: Aceria ficus and Rhyncaphytoptus ficifoliae. Acarologia, 40: 419 429.

Abou-Awad, B.A.; A.M. Metwally and M.M. Al-Azzazy (2005). Environmental management and biological aspects of two eriophyid olive mites in Egypt: Aceria oleae and Tegolophus hassani. Z. Pflanzenkrankh. Pflanzensch, 112(3): 287 - 303.

Abou-Elella, G.M. (1998). Studies on Certain Aspects of Some Predacious Phytoseiid Mites. pp. 91- 94. Ph.D. Thesis, Fac. Agric., Cairo Univ., Egypt.

Aly, F.S. (1994). Biological and Ecological Studies on Some Predacious Mesotigmatic Mites with Special Reference to the Family Phytoseiidae. pp. 220-222. Ph.D. Thesis, Fac. Agric., Cairo Univ. Egypt.

Duso, C. (1992). Role of Amblyseius oberrans (Oud.), Typhlodromus pyri (Scheuten) and Amblyseius andersoni (Chant) (Acari: Phytoseiidae) in Vineyards. III. Influence of Variety Characteris- 
tics on the Success of A.aberrans and T.Pyri. Releases. J. Appl. Ent. 114: 445 - 462.

El-Banhawy, E.M.; S.A. Amer and S.A. Saber (2000). Development and reproduction of the predacious mite Ambyseius cydnodactylon on different prey species, effect of plant leaf texture on the behaviour and reproduction of the predator. J. Plant Diseases and Protection 107: 218 224.

El Sawi, S.A. (1980). Biological Studies on Some Predacious Mites. pp. 68-70. M.Sc. Thesis, Fac. Agric., Cairo Univ., Egypt.

Graut. J.G. and G.I. Richards (1992). Euseius addoensis addoensis, an effective predator of citrus thrips, Scirtothrips aurantii in the eastern Cape Province of South Africa. Exp. Appl. Acarol. 15(1): 1-13.

Harley, M.M. and I.K. Fergusen (1990). The Role of SEM in Pollen Morphology and Plant Systemic In Scanning Electron Microscopy Studies in Taxonomy and Functional and Morphology Ed. By Clangher D., Systemics Association. Special, Volume, 41 pp. 45-68, Clarendon Press. Oxford.

Hulting, F.L.; D.B. ORR and J.J. Obrycki (1990). A computer program for calculation and statistical comparison of intrinsic rates of increase and associated life table parameters. Florida Entomal, 73: $601-612$.

Ibrahim, A.A.E. (1997). Life Table Studies on Some Predacious Mites. pp. 110 - 112. Ph.D. Thesis, Fac. Agric., Cairo Univ., Egypt.

Kennedy, G.G.; R.R. Farrar and R.K. Kashyap (1991). 2-tridecanone - glandular trichome - mediated insect resistance in tomato. Effect on Parastoids and predators of Heliothis zea. In P. A. Hedin (Editor) Naturally occurring pest bioregulator. ACS Symptoms Series 449 Am. Chem. Soc. Wash.: 150-165.
Maas, J.B. (1984). Compendium of Strawberry Diseases. 126 pp. The American Phytopathological Society in Cooperation with Agricultural Research Service, U.S Department of Agriculture, Wachington D.C.

Price, P.W.; C.E. Bouton; P. Gross; B.A. McPheron; J.N. Thompson and E.Weis (1980). Interactions among three trophic levels. Influence of plants on interactions between herbivores and natural enemies. Ann. Rev. Ecol. And Systematics 11: 41-65.

Rodriguez, J.Z.; D.E. Maynard and W.T. Smith. (1960). Effect of soil insecticides and absorbents on plant sugar and resulting effect on mite nutrition. J. Econ. Ent., 53: 491 - 495.

Saber, S.A. and F.M. Momen. (2000). Effect of mating factors on reproduction and sex ratio of the predacious mite Amblyseius zaheri (Acarina: Phytoseiidae). J. Pest Science 73: 113 - 115.

Siitterlin, S. and J.C. van Lenteren (1997). Influence of hairiness of Gerbera jamesonii leaves on the searching efficiency of the parasitoid Encarsia formosa. Biological Control 9: 157 - 165.

Van Haren, R.J. F; M.M. Steenhuis; M.W. Sabelis and O.M.P. de Ponti. (1987). Tomato stem trichomes and dispersal success of Phytoseiulus persimilis relative to its prey Tetranychus urticae. Exp. And Appl. Acarol. 3: 115 - 121.

Walter, D.E. (1992). Leaf surface structure and the distribution of Phytoseius mites (Acari: Phytoseiidae) in Southeastern Australian forests. Aust. J. Zool. 40: 593 - 603.

Wysoki, M. (1985). Other Outdoor Crops in World Crop Pests Spider Mites, Their Biology, Natural Enemies and Control. Volume I B pp. 375 -384. By Helle. W. and M.W. Sabelies, Elsevier, Science Publishers. Amsterdam, The Netherlands. 